\title{
A Maturação do Abacaxi
}

HEITOR W. S. MONTENEGRO

Professor Colaborador da 12. ${ }^{\text {a }}$ Cadeira - Horticultura

Escola Superior de Agricultura "Luiz de Queiroz". USP Piracicaba, S. Paulo 


\section{INTRODUÇÃO}

O ponto exato da colheita das frutas sempre constituiu dentro da fruticultura um dos mais complexos problemas.

É que as transformacões fisiológicas nos frutos são contínuas, não existindo variacões bruscas nos seus compostos principais que pudessem orientar o fruticultor. Não há portanto durante o desenvolvimento da fruta nenhum ponto de referência entre suas características, que possa limitar com precisão qualquer fase da vida do fruto.

A maturação é assim uma fase sem limites precisos.

Sob o ponto de vista frutícola diz-se que um fruto está maduro quando êle atinge um estágio em que é possível a sua consumação. Neste estágio o fruto adquire côr, perfume e suas qualidades organolépticas são máximas.

Ao fruticultor porém. interessa conhecer de um modo prático, o ponto ideal de colheita que, como sabemos, é variável de acôrdo com o fim a que se destina a fruta; se para consumo imediato, se para remessa a longas distâncias ou se para a indústria.

Essas consideracões se aplicam perfeitamente no que diz respeito à maturação do a bacaxi. Esta fruta deixada amadurecer na planta, anresenta selu melhor estado para consumo imediato, porém não se nresta para remessa aos mercados distantes não sòmente devido a sua curta duracão, mas também porque, apresentando-se com tecidos moles, estragam-se fàcilmente no transporte. Por sua vêz, colhido imaturn, êle cessa imediatamente de se enriquecer em acúcares, apresentando assim más qualidades nutritivas e de sabor.

Assim. o problema do plantador é colhêr o abacaxi num estágio tal de maturacão, que êle alcance o mercado em boas condições e que suas qualidades sejam as melhores possíveis.

Várias características têm sido descritas como pontos de referência para a colheita. A primeira seria o secamento das brácteas antes do que não se deve pensar em colhêr e o último a coloração rósea ou avermelhada de todo o fruto. Entre êstes dois estágios há um período relativamente longo com variações nas características do fruto, inclusive na sua coloração. 
Neste trabalho procuramos correlacionar coloração do fruto com qualidade da polpa, visando a orientação do fruticultor para o ponto da colheita.

Ressalvamos porém que os presentes resultados se aplicam sòmente à variedade "Pérola", para a colheita em época normal (novembro-janeiro) e para regiões climáticas semeThantes a Piracicaba.

\section{MATERIAL E METODO.}

Os abacaxis usados na presente pesquisa foram colhidos em uma plantação de 5.000 pés pertencentes aos Irmãos Inforsato e situada na região de Piracicaba.

Foram escolhidos abacaxis em 5 estágios de maturação reconhecidos pelas suas características externas, principalmente sua côr.

Para cada estágio foram tomados 16 frutos separados em quatro grupos de quatro. Eram assim 80 frutos nos 5 estágios.

Todos êles eram aproximadamente iguais nas suas características externas, e fàcilmente identificáveis quanto ao estágio a que pertenciam. A seguir apresentamos as descrições dos cinco estágios:

Estágio - 1 - Os segmentos do fruto são, na sua parte central, de côr verde, passando a verde bem escuro na sua periferia e a marron escuro (quase negro) nos sulcos divisórios.

Em uma pequena área $(7-10 \%)$ da face voltada a noroeste a parte central dos segmentos é de côr verde amarelado e os sulcos marron claro. fibrosa.

A polpa é, na sua totalidade de côr branca, compacta e

Não apresenta nenhum perfume.

Estágio - 2 - Os segmentos da base do fruto apresentam as mesmas côres descritas para a mesma região, no estágio 1. 
$\mathrm{Na}$ parte superior do fruto porém, essas côres são de tonalidade mais clara com o centro dos segmentos de côr amarelada. Na face voltada a noroeste desta região, há uma pequena área de cêrca de 5 a $10 \%$ da total em que os segmentos são quase totalmente amarelados e os sulcos divisórios de côr verde claro.

A polpa é de côr branca com partes amarelo-palha, sendo a primeira firme e a segunda sucosa.

Não exala perfume.

Estágio - 3 - Neste estágio o centro dos segmentos apresenta-se levemente alaraniado, côr que vai se acentuando na direção da base do fruto.

$\mathrm{Na}$ maioria dos frutos, observa-se uma pequena área. com tamanho máximo de $5 \%$ cuịos segmentos são quase totalmente alaranjados com centro levemente avermelhado. Esta zona aparece normalmente na base e do lado menos ensolarado.

A polpa é de côr amarelo-palha com algumas partes esbranquiçadas.

O perfume é muito fraco. quase não se percebendo.

Estágio - 4 - Cêrca de 20 a $40 \%$ do fruto (área essa localizada em sua parte basal e em volta do fruto) apresenta-se de côr alaraniada com o centro dos segmentos avermelhado. Nesta zona os sulcos têm a mesma côr dos segmentos. cosa.

A polpa é totalmente de côr amarelo-palha e muito su-

Exala ela um notável perfume.

Estágio - 5 - Têm as mesməs caracteristicas dos abacaxis do estágio - 4-, apenas a área alaranjada forte atinge um tamanho variável entre 50 e 100 por cento da superfície do fruto.

A diferença de um estágio ao imediatamente superior é de 5 a 7 dias.

Os frutos eram pesados, descascados e da altura do se!: primeiro tôrço, a partir da base, eram retiradas fatias de polpa de pêso variável entre 120 e 170 gramas. Extraia-se o suco de cada fatia com um esmagador de batatas, determinando-se a sua porcentagem. Por titulação com soda acha- 
va-se nele a acidez, expressa em acido cítrico, e determinava-se os sólidos solúveis por meio de um refratômetro de Brix.

A parte basal da polpa era então picada e colocada em pratos numerados para serem degustados por pessoas para isso convidadas.

Os degustadores eram em número de 15. Após a prova preenchiam uma ficha procurando enquadrar cada amostra dentro da seguinte escala: ácido, regular, bom, ótimo e passado.

3. RESULTADOS.

3.1. Apresentamos a seguir os resultados obtidos com as pesagens e análises procedidas com os frutos das amostras dos 5 estágios: 
ESTAGIO - 1 -

\begin{tabular}{|c|c|c|c|c|c|}
\hline 1. a Repetição & & pêso & $\%$ Suco & Brix & Acidez \\
\hline Fruto & $\begin{array}{l}1 \\
2 \\
3 \\
4\end{array}$ & $\begin{array}{l}1500 \\
1250 \\
1400 \\
1330\end{array}$ & $\begin{array}{l}64,0 \\
65,4 \\
65,4 \\
61,6\end{array}$ & $\begin{array}{l}12,4 \\
12,0 \\
12,0 \\
11,0\end{array}$ & $\begin{array}{l}0,35 \\
0,39 \\
0,45 \\
0,47\end{array}$ \\
\hline Média & & 1370 & 64,1 & 11,8 & 0,41 \\
\hline 2. ${ }^{a}$ Repetição & & pêso & $\%$ Suco & Brix & Acidez \\
\hline Fruto & $\begin{array}{l}1 \\
2 \\
3 \\
4\end{array}$ & $\begin{array}{l}1270 \\
1150 \\
1430 \\
1500\end{array}$ & $\begin{array}{l}61,6 \\
57,7 \\
66,7 \\
63,4\end{array}$ & $\begin{array}{l}10,8 \\
11,2 \\
12,0 \\
10,8\end{array}$ & $\begin{array}{l}0,60 \\
0,55 \\
0,49 \\
0,53\end{array}$ \\
\hline Média. & & 1337 & 62,3 & 11,2 & 0,54 \\
\hline 3. Repetição & & pêso & $\%$ Suco & Brix & Acidez \\
\hline Fruto & $\begin{array}{l}1 \\
2 \\
3 \\
4\end{array}$ & $\begin{array}{l}1320 \\
1420 \\
1200 \\
1530\end{array}$ & $\begin{array}{l}66,7 \\
57,7 \\
66,7 \\
66,7\end{array}$ & $\begin{array}{l}11,0 \\
11,0 \\
10,8 \\
13,4\end{array}$ & $\begin{array}{l}0,56 \\
0,53 \\
0,46 \\
0,38\end{array}$ \\
\hline Média & & 1367,5 & 64,4 & 11,5 & 0,48 \\
\hline 4. Repetição & & pêso & $\%$ Suco & Brix & Acidez \\
\hline Fruto & $\begin{array}{l}1 \\
2 \\
3 \\
4\end{array}$ & $\begin{array}{c}1320 \\
1350 \\
1370 \\
1520\end{array}$ & $\begin{array}{c}62,5 \\
62,1 \\
64,3 \\
63,0\end{array}$ & $\begin{array}{c}11,0 \\
12,0 \\
10,8 \\
11,2\end{array}$ & $\begin{array}{l}0,45 \\
0,48 \\
0,49 \\
0,46\end{array}$ \\
\hline Média & & 1390 & 62,9 & 11,2 & 0,47 \\
\hline
\end{tabular}

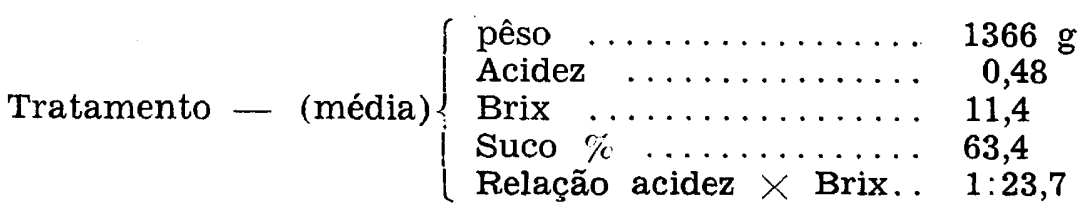


ESTAGIO - 2 -

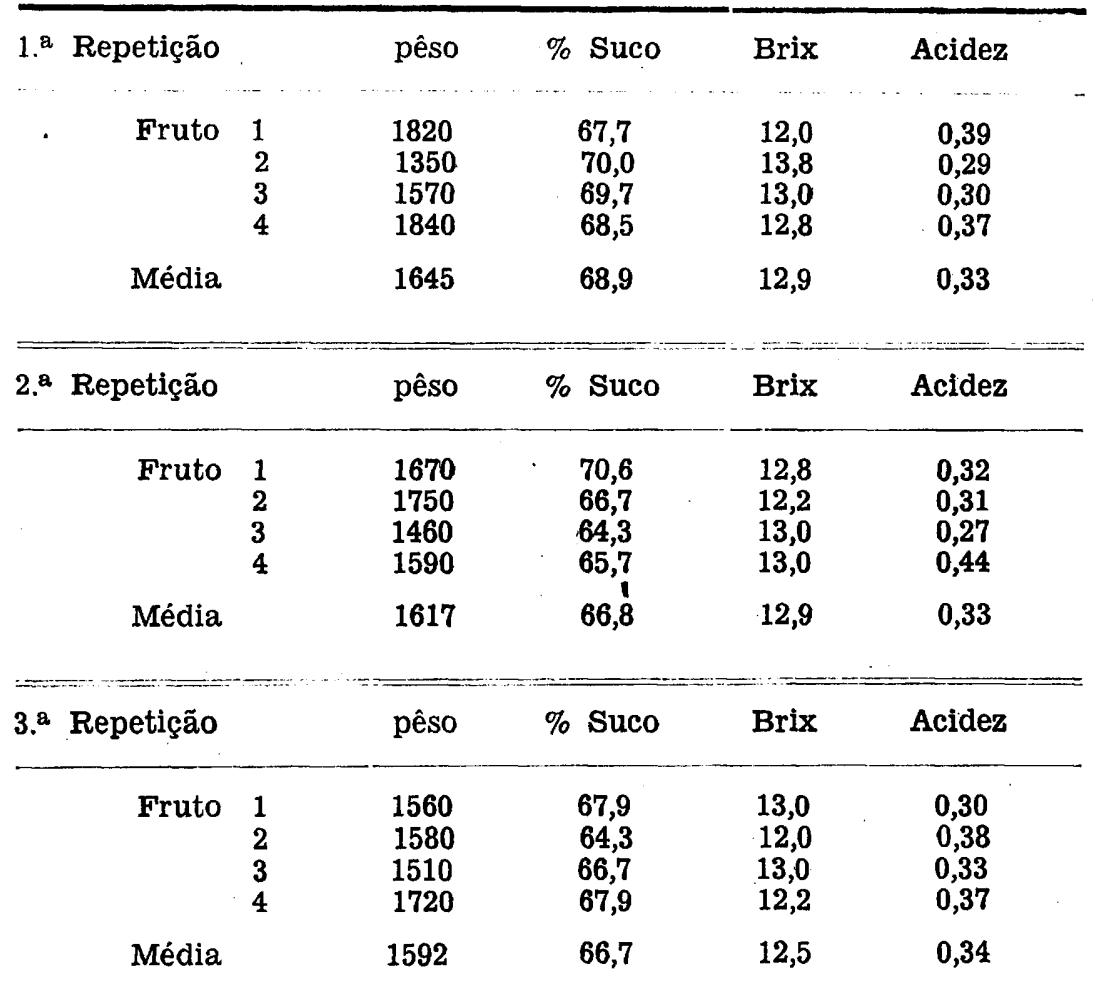

\begin{tabular}{cccccc} 
4. ${ }^{a}$ Repetição & & pêso & \% Suco & Brix & Acidez \\
\hline Fruto & 1 & 1560 & 63,4 & 12,8 & 0,33 \\
& 2 & 1650 & 63,7 & 12,0 & 0,23 \\
& 3 & 1330 & 63,0 & 11,8 & 0,51 \\
& 4 & 2000 & 65,8 & 12,0 & 0,35 \\
Média & 1635 & 63,9 & 12,1 & 0,35 \\
\hline
\end{tabular}

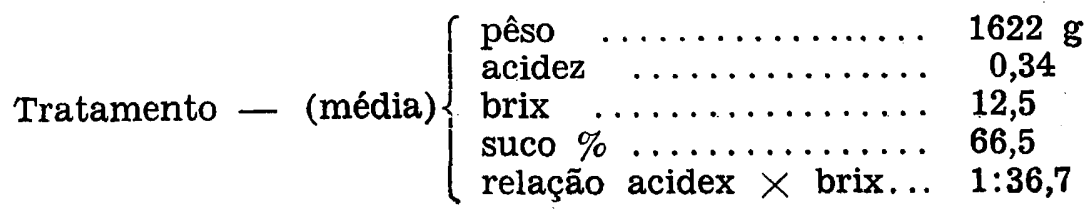


ESTAGIO - 3 -

\begin{tabular}{|c|c|c|c|c|c|}
\hline 1. ${ }^{\mathrm{a}}$ Repetição & & pêso & $\%$ Suco & Brix & Acidez \\
\hline Fruto & $\begin{array}{l}1 \\
2 \\
3 \\
4\end{array}$ & $\begin{array}{l}1210 \\
1630 \\
1520 \\
1570\end{array}$ & $\begin{array}{l}70,0 \\
66,7 \\
66,7 \\
70,4\end{array}$ & $\begin{array}{l}12,8 \\
13,2 \\
12,8 \\
12,8\end{array}$ & $\begin{array}{l}0,37 \\
0,35 \\
0,38 \\
0,34\end{array}$ \\
\hline Média & & 1482 & 68,4 & 12,9 & 0,36 \\
\hline 2. ${ }^{a}$ Repetição & & pêso & $\%$ suco & Brix & Acidez \\
\hline Fruto & $\begin{array}{l}1 \\
2 \\
3 \\
4\end{array}$ & $\begin{array}{l}1650 \\
1470 \\
1720 \\
1470\end{array}$ & $\begin{array}{l}65,7 \\
68,8 \\
64,6 \\
67,9\end{array}$ & $\begin{array}{l}12,0 \\
13,0 \\
12,2 \\
12,2\end{array}$ & $\begin{array}{l}0,28 \\
0,44 \\
0,30 \\
0,28\end{array}$ \\
\hline Média & & 1577 & 66,7 & 12,3 & 0,32 \\
\hline 3.a Repetição & & pêso & $\%$ Suco & Brix & Acidez \\
\hline Fruto & $\begin{array}{l}1 \\
2 \\
3 \\
4\end{array}$ & $\begin{array}{l}1440 \\
1650 \\
1680 \\
1720\end{array}$ & $\begin{array}{l}67,9 \\
65,5 \\
66,7 \\
65,7\end{array}$ & $\begin{array}{l}12,0 \\
13,2 \\
12,8 \\
12,2\end{array}$ & $\begin{array}{l}0,30 \\
0,31 \\
0,31 \\
0,28\end{array}$ \\
\hline Média & & 1622 & 66,4 & 12,5 & 0,30 \\
\hline \multirow[t]{2}{*}{ 4. Repetição } & & pêso & $\%$ Suco & Brix & Acidez \\
\hline & $\begin{array}{l}1 \\
2 \\
3 \\
4\end{array}$ & $\begin{array}{l}1890 \\
1540 \\
1970 \\
2040\end{array}$ & $\begin{array}{l}64,6 \\
66,7 \\
71,0 \\
63,7\end{array}$ & $\begin{array}{l}13,0 \\
12,2 \\
13,0 \\
12,6\end{array}$ & $\begin{array}{l}0,30 \\
0,30 \\
0,30 \\
0,33\end{array}$ \\
\hline Média & & 1860 & 66,5 & 12,7 & 0,30 \\
\hline Tratamento & $\longrightarrow$ & (média) & $\begin{array}{l}\text { pêso } . . . \\
\text { acidez } \\
\text { Brix } \ldots \\
\text { Suco \% } \\
\text { Relação aci }\end{array}$ & $\begin{array}{l}\cdots \\
\cdots \\
\times b\end{array}$ & $\begin{array}{lc}\ldots & 1635 \mathrm{~g} \\
\ldots & 0,32 \\
\ldots & 12,6 \\
\ldots & 67,0 \\
\ldots & 1: 39,3\end{array}$ \\
\hline
\end{tabular}


ESTÁGIO - 4 -

\begin{tabular}{|c|c|c|c|c|c|c|}
\hline \multicolumn{3}{|c|}{ 1. ${ }^{\mathrm{a}}$ Repetição } & pêso & $\%$ Suco & Brix & Acidez \\
\hline & Fruto & $\begin{array}{l}1 \\
2 \\
3 \\
4\end{array}$ & $\begin{array}{l}1460 \\
1300 \\
1660 \\
1390\end{array}$ & $\begin{array}{l}69,0 \\
70,0 \\
67,8 \\
69,3\end{array}$ & $\begin{array}{l}14,0 \\
13,8 \\
13,4 \\
12,8\end{array}$ & $\begin{array}{l}0,28 \\
0,26 \\
0,31 \\
0,27\end{array}$ \\
\hline & Média & & 1437 & 69,1 & 13,5 & 0,28 \\
\hline $2{ }^{\mathrm{a}}$ & Repetição & & pêso & $\%$ Suco & Brix & Acidez \\
\hline & Fruto & $\begin{array}{l}1 \\
2 \\
3 \\
4\end{array}$ & $\begin{array}{l}1430 \\
1500 \\
1560 \\
1460\end{array}$ & $\begin{array}{l}69,3 \\
71,9 \\
67,8 \\
69,3\end{array}$ & $\begin{array}{l}13,0 \\
13,8 \\
13,2 \\
11,2\end{array}$ & $\begin{array}{l}0,31 \\
0,25 \\
0,28 \\
0,43\end{array}$ \\
\hline & Média & & 1487 & 69,5 & 12,8 & 0,32 \\
\hline
\end{tabular}

\begin{tabular}{rrrrrr}
$3 .^{\text {a }}$ Repeticão & & pêso & \% Suco & Brix & Acidez \\
\hline Fruto & 1 & 1550 & 65,4 & 13,4 & 0,38 \\
& 2 & 1370 & 65,4 & 14,2 & 0,37 \\
& 3 & 1600 & 67,9 & 13,0 & 0,33 \\
4 & 1620 & 65,6 & 13,0 & 0,31 \\
Média & 1535 & 66,1 & 13,4 & 0,35
\end{tabular}

\begin{tabular}{|c|c|c|c|c|c|c|c|}
\hline \multirow{3}{*}{$4 .{ }^{a}$} & \multirow{2}{*}{$\begin{array}{r}\text { Repetiçāo } \\
\text { Fruto }\end{array}$} & & pêso & & Suco & Brix & Acidez \\
\hline & & $\begin{array}{l}1 \\
2 \\
3 \\
4\end{array}$ & $\begin{array}{l}1590 \\
1560 \\
1530 \\
1610\end{array}$ & & $\begin{array}{l}64,3 \\
64,3 \\
66,7 \\
65,6\end{array}$ & $\begin{array}{l}13,0 \\
12,6 \\
12,8 \\
12,2\end{array}$ & $\begin{array}{l}0,30 \\
0,35 \\
0,41 \\
0,27\end{array}$ \\
\hline & Média & & 1572 & & 65,2 & 12,6 & 0,33 \\
\hline Tra & atamento & - & (média) & $\begin{array}{l}\text { acidez } \\
\text { brix. } \\
\text { Suco } \\
\text { relaçã } \\
\text { pêso }\end{array}$ & 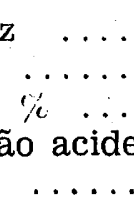 & ․ & $\begin{array}{ll}\ldots & 0,32 \\
\cdots & 13,1 \\
\ldots & 67,5 \\
\ldots & 1: 40,9 \\
\ldots & 1507 \mathrm{~g}\end{array}$ \\
\hline
\end{tabular}


ESTAGIO - 5 -

\begin{tabular}{rrrrrr}
\hline 1. ${ }^{\text {a }}$ Repetição & & pêso & \% Suco & Brix & Acidez \\
\cline { 1 - 1 } Fruto & 1 & 1590 & 75,8 & 14,0 & 0,28 \\
& 2 & 1570 & 71,5 & 13,0 & 0,28 \\
& 3 & 1370 & 75,0 & 13,4 & 0,30 \\
4 & 1580 & 75,0 & 12,0 & 0,32 \\
Média & 1527 & 74,3 & 13,1 & 0,29
\end{tabular}

\begin{tabular}{cccccc}
\hline 2." & & pêso & \% Suco & Brix & Acidez \\
\hline Fruto & 1 & 1340 & 77,0 & 14,0 & 0,28 \\
& 2 & 1610 & 75,0 & 12,6 & 0,38 \\
& 3 & 1700 & 70,6 & 13,2 & 0,39 \\
& 4 & 1430 & 71,5 & 12,8 & 0,35 \\
Média & 1520 & 73,5 & 13,1 & 0,35
\end{tabular}

\begin{tabular}{|c|c|c|c|c|c|c|}
\hline 3. ${ }^{a}$ Repetição & & pêso & & Suco & Brix & Acidez \\
\hline Fruto & $\begin{array}{l}1 \\
2 \\
3 \\
4\end{array}$ & $\begin{array}{l}1700 \\
1500 \\
1470 \\
1300\end{array}$ & & $\begin{array}{l}69,0 \\
70,4 \\
75,0 \\
69,3\end{array}$ & $\begin{array}{l}13,0 \\
13,0 \\
13,6 \\
13,0\end{array}$ & $\begin{array}{l}0,24 \\
0,27 \\
0,27 \\
0,27\end{array}$ \\
\hline Média & & 1492 & & 70,9 & 13,1 & 0,26 \\
\hline 4. ${ }^{a}$ Repetição & & pêso & $\%$ & Suco & Brix & Acidez \\
\hline Fruto & $\begin{array}{l}1 \\
2 \\
3 \\
4\end{array}$ & $\begin{array}{l}1400 \\
1550 \\
1450 \\
1520\end{array}$ & & $\begin{array}{l}71,5 \\
71,9 \\
68,8 \\
73,4\end{array}$ & $\begin{array}{l}15,0 \\
13,0 \\
13,2 \\
12,8\end{array}$ & $\begin{array}{l}0,29 \\
0,31 \\
0,28 \\
0,33\end{array}$ \\
\hline Média & & 1480 & & 71,4 & 13,5 & 0,30 \\
\hline Tratamento & - & (média) & $\begin{array}{l}\text { acidez } \\
\text { brix } \\
\text { Suco } \\
\text { Relaçã } \\
\text { pêso }\end{array}$ & $\begin{array}{l}\ldots \\
\ldots \\
\% \\
\text { \% } \\
\ldots \\
\ldots\end{array}$ & $\begin{array}{l}\cdots \\
\ddot{x}\end{array}$ & $\begin{array}{ll}\text {. } & 0,30 \\
\ldots & 13,2 \\
\ldots & 72,5 \\
\ldots & 1: 42,5 \\
. . & 1504 \mathrm{~g}\end{array}$ \\
\hline
\end{tabular}




\subsection{Degustação.}

Abaixo relacionamos os resultados obtidos pela degustação das amostras dos 5 estágios. São êles expressos em percentagem do total de opiniões sôbre as amostras de cada estágio.

\begin{tabular}{llcccc}
\hline Classificação & $10^{\circ}$ Est. & $2^{\circ}$ Est. & $3 .^{\circ}$ Est. & $4 .^{\circ}$ Est. & $5 .^{\circ}$ Est. \\
\hline Ácido & 100,0 & - & - & - & - \\
Regular & - & 46,6 & 20,0 & $\overline{-}$ & - \\
Bom & - & 46,6 & 60,0 & 6,8 & - \\
Otimo & - & 6,8 & 20,0 & 66,6 & 40,0 \\
Passado & - & - & - & 26,6 & 60,0 \\
\hline
\end{tabular}

\section{DISCUSSÃO E RESULTADOS}

As análises dos frutos nos diversos estágios mostraram que a coloração da casca é um índice valioso para saber se aquilatar o estado de maturação do abacaxi.

No gráfico 1 pode-se observar a evolução da acidez, do brix e da percentagem de suco nos diversos estágios de maturação. Nota-se o aumento contínuo do brix (açúcares) e suco e o decréscimo da acidez.

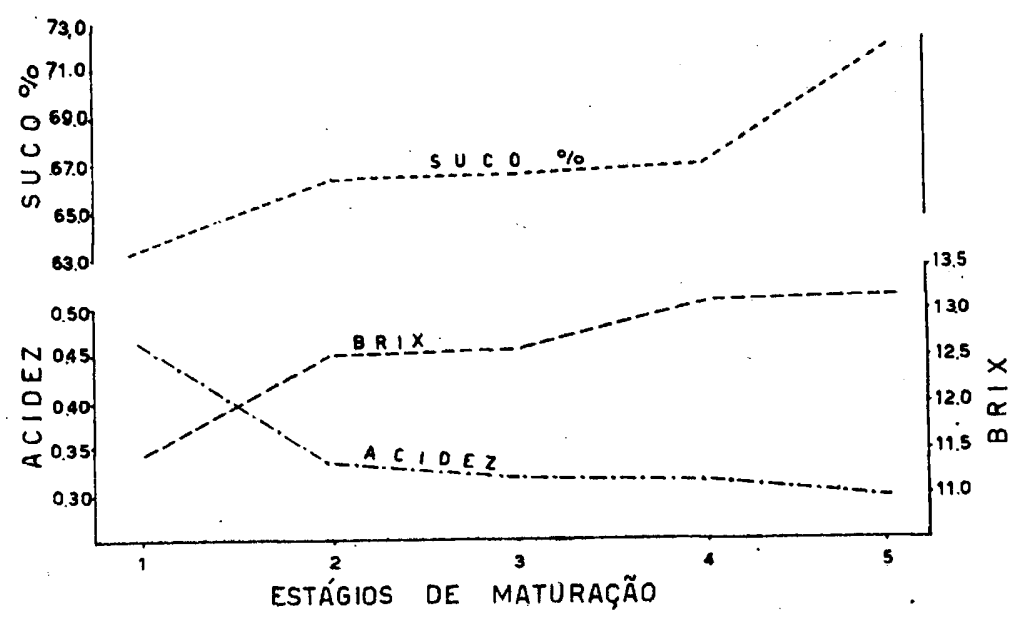


É de se salientar as bruscas variações do brix e acidez entre os estágios 1 e 2 o que nos parece proporcionar um ótimo ponto de referência para a avaliação da maturação.

Essas variações bruscas nos parecem poder ser correlacionadas com as modificações da polpa que causam as mudanças da coloração branca para amarelo-palha. Essa modificação na côr da polpa também nos afigura um ótimo ponto de referência para a maturação do abacaxi.

A análise do teste de degustação mostra resultados bastantes interessantes. Como é natural observa-se entre os provadores uma variação de paladar. Uns apreciando mais os frutos com maior acidez, outros preferindo os mais doces.

Apesar disso os resultados dêsse teste nos parecem excelentes. Há uma regularidade bastante normal de opiniöes entre os estágios.

Outro ponto interessante a se observar é a unanimidade de opiniões quanto aos frutos do primeiro estágio considerado por todos como verdes ou muito ácidos, e apesar disso a sua relação acidez $\times$ brix atingiu uma média de $1: 23,7$ e sua porcentagem de sucos, 63,4. O que nos causa espécie é o rato de que nas especiticaçóes oficiais para a exportaçäo do abacaxi, de acôrdo com o decreto tederal n. $\left.76^{\prime}\right)^{\prime} \%$ de 19 de agósto de 1941, os mínimos permitidos são: relação ácido $\times$ solidos solúveis 1:8 a 1:10 (zona central e meridional) e porcentagem de suco igual a 40.

Comparando-se os resultados das análises dos frutos do primeiro estágio e os resultados do teste de degustaçáo com esses minimos podemos avaliar o grau de maturação dos irutos que, dentro das especificaçoes oficiais, podem ser remetidos para o exterior. São trutos demasiadamente verdes. Essas especificaçöes oficiais referentes a permissão para exportação, julgamos deverem ser modificadas.

No que diz respeito ao ponto ótimo de maturação para a colheita, consideramos como tal o estágio número 3 , para as regiões que não requeiram um transporte prolongado, e o estágio 2 para as que o requeiram.

Para a indústria o estágio 1 é o melhor pois a polpa dos frutos ainda está completamente firme, resistindo bem à máquina descascadora. 


\section{CONCLUSÕES}

1 - Em regiões sujeitas a um mesmo clima, e na mesma época de colheita, há uma correlação entre grau de maturação e coloração externa do fruto.

2 - Considera-se como melhor ponto de colheita para a variedade "Pérola' nas regiões mais próximas dos mercados, o estágio número 3 e, para aquelas mais distantes, o número 2.

3 - Para a indústria é considerado como melhor o estágio n. ${ }^{0} 1$.

4 - Os mínimos exigidos para a relação de acidez-sólidos solúveis e para a porcentagem de suco, nos frutos destinados à exportação são muito baixos.

\section{SUMMARY}

In the present work it was sougth to correlate the coloration of the fruit of Ananas comosus variety Perola with the pulp quality, aiming at the orientation of the fruit grower to the correct time of harvest.

Pineapple fruit was chosen in 5 stages of maturation recognized by its external characteristics, principally its color.

The fruits of each stage of maturation were analysed, determining the weight, the percentage of soluble solids, and relation of acid to soluble solids.

At the same time a test was made classifying the fruits as acid, regular, good, excellent, and spoiled.

A correlation was found between the external coloration of the fruit and the degree of maturation.

Concluding from this that the best time to harvest the variety Perola is in the third stage in the regions closest to the market and in the second stage in the regions which are farther away.

For the cannery industry the fruit should be harvest in the first stage. 


\section{BIBLIOGRAFIA}

DAVIES, R. - 1928 - Fruit storage investigations, 1 - Storage investigations of pineapple in South Africa. Science Bulletin n. $71-27$ p. South Africa.

HENRICKSEN, H.C. - 1928 - Some pineapple problems. Art. 22 Fruit maturity. Agricultural Notes - n.0 $41-5 \mathrm{p}$.

KOPP, A. 1929 - Les Ananas. 283 p. Editeur Paul Lechevalier. Paris. PY, C; M.A. TISSEAU; B. CURY; F. ABMADA - 1957 - La culture de l'ananas en Guinée. 331 p. I.F.A.C. Paris. 